\title{
Building Brand Equity and Consumer Trust Through Radical Transparency Practices
}

Part of the Advances in Marketing, Customer Relationship Management, and EServices Book Series

Elena Veselinova (Goce Delčev University of Štip, Macedonia) and Marija Gogova Samonikov (Goce Delčev University of Štip, Macedonia)

\section{Description:}

The creation of business value and competitive advantage is crucial to any company in the modern corporate sector. By developing positive relationships with consumers, businesses can better maintain their customers' loyalty.

\section{Building Brand Equity and Consumer Trust Through Radical}

Transparency Practices is an innovative reference source for emerging scholarly perspectives on the role of branding in organizational contexts and techniques to sustain a profitable and honest relationship with consumers. Highlighting a range of pertinent topics such as risk management, product innovation, and brand awareness, this book is ideally designed for managers, researchers, professionals, students, and practitioners interested in the development of value creation in contemporary business.

Building Brand Equity and Consumer Trust Through Radical Transparency Practices

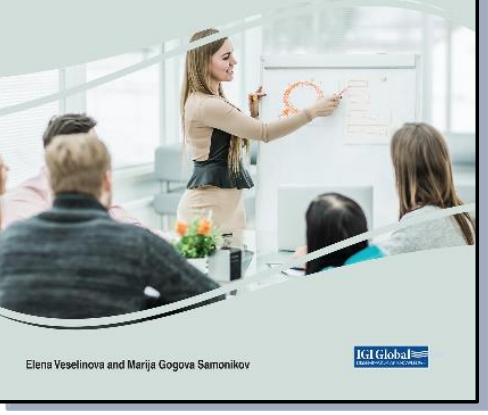

\section{Topics Covered:}

- Brand Awareness

- Corporate Governance

- Employee Engagement

- Product Innovation
- Risk Management

- Supply Chain Management

- Workforce Quality

Hardcover: $\$ 225.00$

E-Book: $\$ 225.00$

Hardcover + E-Book: $\$ 270.00$ 